\title{
Multi-objective land allocation for zoning of ecosystem services in mountain forests
}

\author{
Roman Sitko*, Lubomír Scheer \\ Technical University in Zvolen, Faculty of Forestry, T. G. Masaryka 24, SK-960 01 Zvolen, Slovak Republic
}

\begin{abstract}
The paper proposes a system for zoning of mountain areas based on the level of provisioning of ecosystem services. Techniques of multi-objective land allocation were applied to allocate complementary and conflicting objectives. The zoning system consists of four phases: i) Identification of criteria for the evaluation of ecosystem services; ii) Quantification of criteria for three different forestland states; iii) Evaluation of potential and effect of the forest on providing the ecosystem services and iv) Zoning of ecosystem services with their prioritization and spatial allocation of support measures. The study was conducted in the Tatra Mountains (Slovakia). Erosion control, avalanche control, wood production and cultural services were evaluated. The greatest differences between potential and effect of the evaluated ecosystem services were identified for the avalanche control. A comparison of our results with the existing (control) map of ecosystem services has proved that the proposed system is a potent means for multi-objective forest planning.
\end{abstract}

Key words: decision support; ecosystem services; fuzzy logic; mountain forests; multi-objective land allocation

Editor: Tomáš Hlásny

\section{Introduction}

One of the topical tasks of the present is the sustainable management of natural resources. In forest landscapes, we observe an increasing demand on various provisioning, regulating, supporting and cultural ecosystem services such as quality and quantity of fresh water, wood as a renewable source of energy, mitigation of natural disaster consequences such as flooding, drought, avalanches, landslides, increasing demand on recreation in the forest etc. The concept of multi-objective forest planning is suitable on satisfying such a wide range of alternatives (Pukkala 2010).

Origin of the multi-objective (multiple-use) concept can be found in Germany and the USA. The concept has been developing from the 1960s in Nordic countries too (Hytönen 1995). Depending on the tradition of forest management, natural and socio-economic conditions, two main approaches can be distinguished: the segregation and integration approach (Boncina 2011). The segregation approach is preferred by countries with large forest areas and low population density (e.g. Canada, Russia). Multiple objectives are achieved on a larger scale by dividing the forests to areas with single but different uses. In Central Europe, the integration approach was preferred. That approach maintains more uses at the same time and in the same forest area. The importance of particular objectives can be different, but unlike the segregation approach, the most important objectives do not exclude others, not even conflicting objectives. Those are only given a lower priority and trade-off are evaluated.

The methodology of Papánek (1978) is among the first ones in Central Europe representing a practical handbook for forest managers on how to incorporate the integrated approach to forest planning. The author introduced methods for designation of forest areas with different prioritization of ecosystem services (e. g. category of the forest, functional type and spectrum, management designation of the forest). Simoncic et al. (2013) consider as an important part of the integration approach the designation of priority areas, which are relatively more important for selected objectives than forests outside of these areas. Priority areas are used as a general term for areas where selected ecosystem services (goods, benefits, functions) play important role in multi-objective forest planning. The latter authors distinguished two main types of priority areas widely used in the Central European forestry: forest function areas (zones for selected ecosystem services) and protected areas. The authors discuss some crucial reasons why priority areas are used in forest planning:

- Priority areas are an important tool for differentiating management objectives and measures within large forest areas (Bettinger et al. 2009) 
- Priority areas are an important for public participation and forest sector cooperation in spatial planning (Betteliny et al. 2000; Kangas et al. 2010)

- Priority areas provide a spatial framework for allocation of financial compensations and subsidies and can therefore be a useful tool for the implementation of forestry policy (Cubbage et al. 2007).

Participation of various stakeholders in multi-objective planning highlights the need of evaluation of numerous management alternatives and requires the utilizing of up-to-date tools and methods for objective and transparency designation of priority areas. In multi-objective forest planning, forest plans are evaluated using various multicriteria decision methods and multi-objective optimization algorithms (Pukkala 2010). An extensive overview of decision support tools to operationalize the ecosystem services concept presents Grêt-Regamey et al. (2017). Nine state-of-the-art European forest decision support systems (DSS) focused on ecosystem services provisioning at the landscape scale were assessed by Nordström et al. (2019). Reynolds et al. (2008) divides optimization techniques used in decision support system into three general classes:

- Multicriteria decision models

- Artificial neural networks

- Knowledge-based systems

Multicriteria decision models help to structure complex decisions in forest management by decomposing multiple objectives to relatively simple, measurable criteria. Such an approach brings a transparent and comprehensive way for comparison various alternatives especially in DSS with public participation.

The advantage of Artificial neural networks (ANN) is that it facilitates analysis of the more qualitative aspects of the decision-making process. The necessity of large data set for network training and testing purposes have some limitations in forest management. Another limitation on the use of ANN arises from the complex mathematical nature of this technique, which often causes it to be a black box. This worsens the explanation capabilities of the results to the end user.

On the other hand, the architecture of knowledgebased systems (KBS) make those systems a white box, and therefore they have become more successful in addressing forest management issues. The main feature of KBS is to make decisions about the system based on knowledge of its behavior while system behavior is formalized in knowledge base by expert. Derived conclusions are presented in relatively simple and intuitive terms and thus enables to involve potentially many managers, scientists and stakeholders into the decision process (Reynolds et al. 2008).

For the tasks of multi-objective optimization and spatial allocation of priority areas play the very important role analytical tools of GIS. They enlarge DSS into spatial decision support systems (Tuček \& Sitko 2000). In the case of complementary objectives there are used ranking procedures based on results of the multi-criteria evaluation. In case of the task of multi-objective land allocation under conditions of conflicting objectives clear priorities cannot be set. Mathematical programming solutions can work quite well in instances where only a smaller number of alternatives are being addressed. However, in the case of huge GIS raster data sets and many management objectives involvements, the choice of heuristic methods is more appropriate (Eastman 2016).

To our knowledge, the approach integrating analytical tools of GIS and DSS for zoning of ecosystem services in Central Europe mountain forests is missing. The aim of the current study is therefore to (1) propose the workflow for solving the complex multi-objective land allocation tasks using a scientifically sound and practical approach and (2) demonstrate precise zoning of priority areas and spatial allocation of measures that support respective ecosystem services (support measures). We consider in this study both complementary and conflicting objectives typically occur in the Central European mountain forests.

\section{Materials and methods}

\subsection{Model territory}

The model territory is a catchment situated in the highest mountain range of the Carpathians, the Tatra Mountains (Fig. 1). In 2004, around 12,000 ha of forests were completely damaged due to windthrow. In next 5 years, other 1,545 ha of forests died due to a bark beetle outbreak (Nikolov et al. 2010). A part of the devastated forests is located in the model territory. The size of the territory is 2,493 ha. Its valuable biotopes and areas are included in the European network of protected areas NATURA 2000. The territory has a high-mountain character with a rugged terrain relief with altitudes ranging from 1,100-2,052 $\mathrm{m}$ a.s.l. The long-term average air temperature varies from 0.2 to $4.4^{\circ} \mathrm{C}$ depending on the altitude, in vegetation period (May-August) from 6.6 to $11.9^{\circ} \mathrm{C}$. The long-term annual sum of precipitation is $1485 \mathrm{~mm}$. The site is predominantly made up of metamorphites. Cambisoil occurs in the lowest altitudes, followed by podsols, and in the highest altitudes, the groups of ochric soils can be found. Phytosociologically, in the model area predominates the associations SorbetoPiceetum and Cembreto-Piceetum which continuously pass to Cembreto-Mughetum and to acidic associations of Mughetum acidofilum. Norway spruce is dominant, covers $32 \%$ of the territory. Mountain ash (19\%) and Swiss stone pine (5\%) are admixed and European larch occurs only rarely. The dwarf pine above the timberline covers $7 \%$ of the territory. The rest of the territory (47\%) is covered by grassland or is not covered with vegetation. 


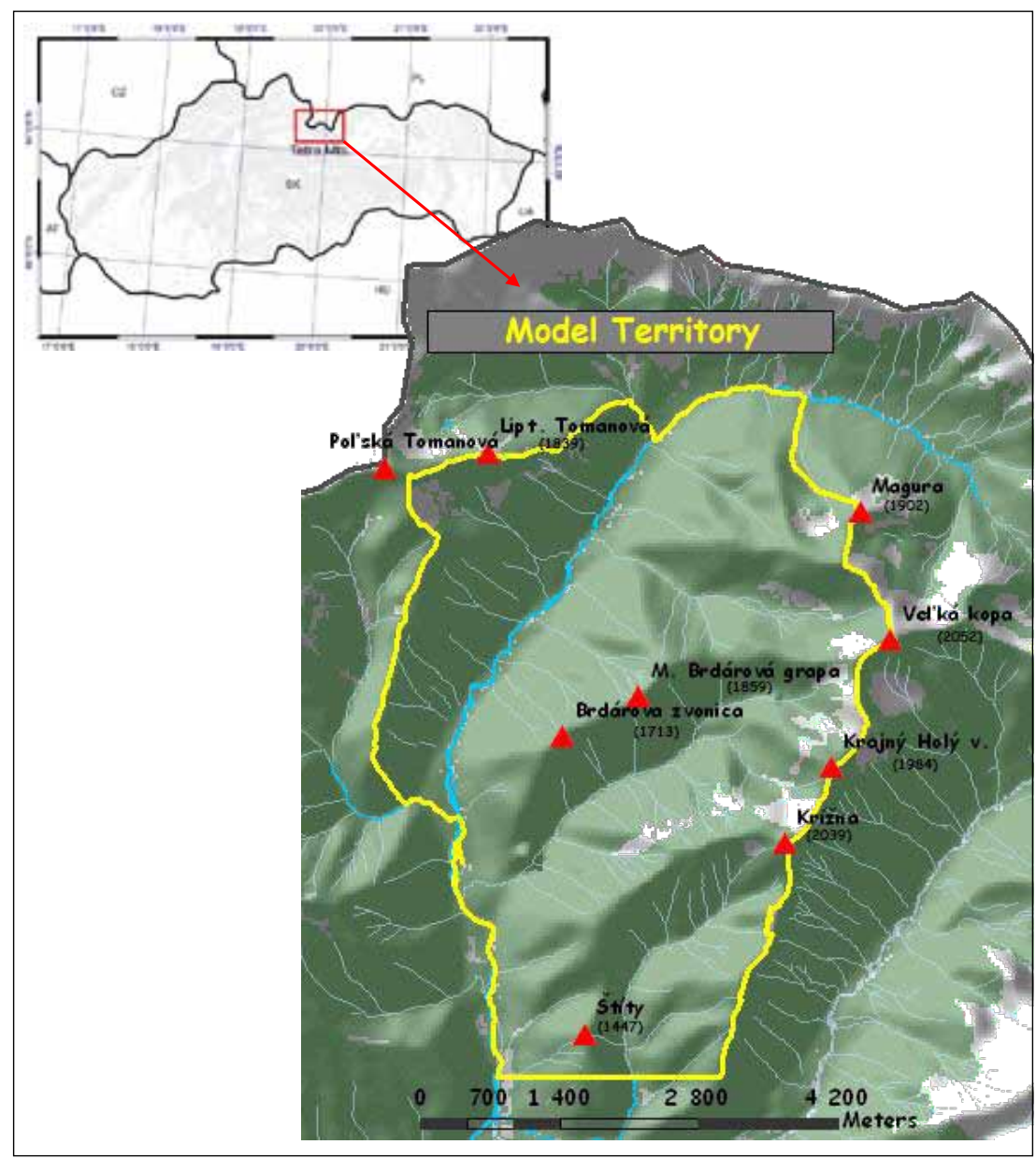

Fig. 1. Location of the model territory (yellow borderline) in the Tatra Mountains (located in the red rectangle), Slovakia (SK). The shaded slopes with runoff channels (white lines) and permanent stream (blue line). Green areas represent the forest stands with any tree/dwarf pine cover, white/grey areas the stands without any tree/dwarf pine cover. Elevation is displayed in the parenthesis.

\subsection{Data sources}

The investigated ecosystem services were: avalanche control, erosion control, wood production and cultural services of the forest. The group of cultural services is related to the preference of nature conservation in the model territory. By favoring that objective, the forest provides multiple cultural ecosystem services, e.g.: recreation, spiritual and aesthetic values, mental and physical health etc.

The following data sources were used:

- digital elevation model (DEM)

- geological and pedological maps (Landscape atlas of the Slovak Republic, 2013)

- classification of vegetation cover from IKONOS satellite data (Scheer \& Sitko 2007a)

- map of avalanche tracks (provided by Center of Avalanche Prevention, Slovakia)

- map of protected areas (provided by Slovak Environment Agency)

- map of management group of forest types (provided by National Forest Center, Slovakia)
- map of forest compartments (provided by National Forest Center, Slovakia)

- data from the forest management databases (provided by National Forest Center, Slovakia)

- climatic data from meteorological stations (provided by Slovak Hydrometeorological Institute).

\subsection{Workflow for the allocation of priority areas}

The term "priority areas" is used for designating areas under specific management objectives and setting spatially defined management priorities in nature conservation planning (Simoncic et al. 2013). The result of the here proposed workflow is zoning of priority areas, based on:

- mapping of spectrum of ecosystem services, which express the potential of forest to provide selected services

- spatial allocation of measures that support respective ecosystem services (support measures), in areas with 
the greatest difference between potential and effect of the forest on providing the services

We use multi-objective optimization techniques implemented in GIS for allocation of land for the specific objectives. This is preceded by process of evaluation of ecosystem services. The knowledge base was formalized for evaluation of potential of forestland for provision of ecosystem services (hereinafter called service potential) as well as service effect, which characterize actual provision of ecosystem services. The proposed workflow consists of four consecutive phases (Fig. 2).

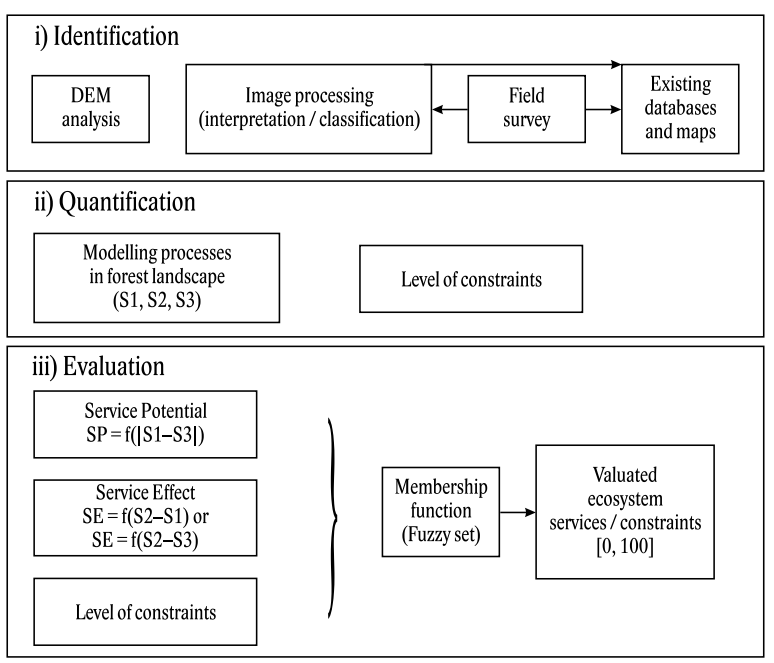

iv) Zoning

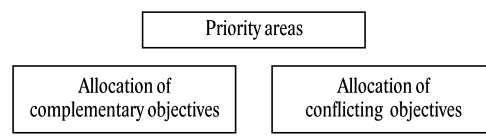

Fig. 2. Scheme of the proposed workflow for evaluation of ecosystem services and allocation of priority areas: i) Identification of criteria important for evaluation of ecosystem services; ii) Quantification of criteria for three states of the forest - optimal (S1), actual (S2) and extreme (S3); iii) Evaluation of potential and effect of the forestland with providing the ecosystem services - identifying differences between scenarios and transforming them through defined membership functions to truth values $0-100(0-$ no potential/effect of service, $100-$ the highest potential/effect of service); iv) Zoning of ecosystem services with their prioritization and allocation of support measures for complementary as well as conflicting objectives.

i) Identification of criteria - phase aimed to choosing the criteria important for the assessment of ecosystem services. The selection of criteria is closely linked to the method of their quantification in the next phase of the workflow.

Criteria for evaluation of soil protection services: rainfall and runoff; soil erodibility; altitude, inclination, shape and length of slopes; overall slope of avalanche tracks; contributing area; density and type of vegetation cover.

Criteria for evaluation of wood production service: index of the reduced growing stock level; stocking; the proportion of the assortments of I.-III.A assortment class; coefficient of slenderness; total mean value increment.

Important requirement is exclusion of wood production from prioritization for areas designated for nature conservation which leads to support cultural ecosystem services.

Geoinformatics technics such as DEM analysis, spatial interpolation, tree species classification and identification of avalanche tracks based on image data were utilized to update and enhance the existing databases and maps. The field survey was realized to gain auxiliary data for supervised classification of tree species composition.

ii) Quantification of criteria - modeling of the soil erosion, avalanche processes, wood production in technical units and with the various influence of the forest structure as well as specifying the level of constraints resulting from nature conservation objectives, were performed. In order to be able to evaluate both the potential and the effect of fulfilling ecosystem services in next phase, quantification of the criteria was done for the following three scenarios:

- optimal state of forest (S1) characterized by natural altitudinal occurrence of tree species and by typological classification of the territory into management groups of forest types;

- real state of forest (S2) given by the actual state of forest stands;

- extreme state of forest stands (S3) with no trees at the stands.

Quantification of soil erosion for all three scenarios was based on the semi-empirical model MUSLE (Moor \& Wilson 1992). The model quantifies the average soil loss in tons per hectare per year. S1 scenario expresses minimum soil loss modeled in the model territory, scenario $\mathrm{S} 2$ actual erosion, and S3 scenario is considered as maximum soil loss.

Quantification of criteria for evaluation of avalanche control is based on identification of avalanche trigger zones and modeling maximum runout distance of avalanche tracks. Maximum avalanche runout distance was modeled by Alfa-Beta empirical model (McClung $\&$ Mears 1991). The expert system of the identification of avalanche trigger zones was developed in collaboration with the Avalanche Prevention Center, Slovakia. The system quantifies the plausibility of avalanche triggering based on the assessment of three groups of factors: climatic, topographical and land cover. Runout distance of avalanche tracks was modeled for all potential trigger zones identified assuming no action of trees in S3 scenario as well as optimal tree composition in S1 scenario. S2 scenario reflects actual occurrence of avalanche tracks recorded in map of avalanche tracks updated utilizing Ikonos satellite data.

Real wood production of the forest (S2) is assessed based on four criteria quantifying the quantity, quality, and safety of wood production. The wood production for optimal state of the forest (S1) was quantified based on the results of simulation using the semi-empirical tree growth simulator Sibyla (Fabrika \& Durský 2006). The 
simulation was processed for the plots representing management groups of forest types occurring in model territory. Total mean value increment (TMVI) was quantified in Eur per hectare. In the case of the extreme state of the forest stand (S3), we expect no wood production.

Criterion for cultural services was quantified by a degree of the territorial protection from 1 to 5 (1-the lowest, 5-the highest degree), as defined by the national legislation. However, quantification was not performed for all three scenarios. Constraints arising from nature conservation issues have at the whole model territory the high importance because the whole area is in a long-term under the $4^{\text {th }}$ or the $5^{\text {th }}$ degree of territorial protection and there are situated sites protected by the NATURA 2000 too. Therefore, we simplify the quantification procedure by assuming that the value of the criterion used for the optimal state (S1) and the actual state of the forestland (S2) is identical.

iii) Evaluation of ecosystem services - in order to compare various ecosystem services and assess the uncertainty in the evaluation process, the evaluation concept utilizing the fuzzy logic was applied. As a main tool of the evaluation, the membership function is defined. The function is created by expert experience. The domain values of the function are formed by the quantified criteria, measured in technical units or by the indexes without any units (e.g. t ha ${ }^{-1}$ year $^{-1}, \mathrm{~m}^{3} \mathrm{ha}^{-1}$, degrees etc.). Those are transformed into a continuous-valued metric, known as the truth value (Reynolds \& Hessburg 2005). Truth value expresses the degree of support for proposition that the respective criterion or ecosystem service has the highest importance of all evaluated services. We use interval of truth values $[0,100]$, where 100 represents the highest importance of ecosystem service. Two general features of ecosystem services were evaluated:

- Service Potential (SP) - potential of forestland for provision of ecosystem services; membership function is defined for domain values derived as the absolute difference between quantified scenarios S3 and $\mathrm{S} 1$. The greater absolute difference between scenarios means the greater service potential (e.g. greater difference of maximum soil loss for no forest cover (S3) and minimum soil loss controlled by optimal forest (S1) means greater erosion control potential):

$$
S P=f(|S 3-S 1|)
$$

- Service Effect (SE) - actual provision of ecosystem services; membership function is defined for domain values derived as the difference of quantified scenarios S2 and S3 or S1. The greater the difference between scenarios, the greater the service effect (e.g. greater difference between actual soil loss modeled for actual forest (S2) and minimum soil loss modelled for optimal forest (S1) means greater erosion control effect):

$$
\begin{aligned}
& S E=f(S 2-S 1), \text { if } S 1<S 3 \\
& S E=f(S 2-S 3), \text { if } S 3<S 1
\end{aligned}
$$

The development system for knowledge base NetWeaver was used to define the membership func- tions. It is embedded in the EMDS (Ecosystem Management Decision Support) software (Reynolds 2013). The system provides decision support for landscape-level analyses trough logic and decision engines integrated with ArcGIS software (ESRI 2011).

The approach used for membership function creation we describe on the evaluation of the erosion control service of the forest. The membership function was determined according to the expert knowledge of tolerable or compensated erosion. The function (Fig. 3) starts from the level of tolerable soil loss, $7.5 \mathrm{tha}^{-1}$ year $^{-1}$ (Šály \& Midriak 1995). The membership function is rising from that point steeper until the breakpoint of $22.5 \mathrm{t} \mathrm{ha}^{-1}$ year $^{-1}$. It is considered as a boundary between moderate and severe soil loss by the last cited paper. The forestland which can prevent the soil loss above or equal to $75 \mathrm{t} \mathrm{ha}^{-1}$ year $^{-1}$ reaches the highest truth value (100). The same function was used for evaluation SP as well as SE.

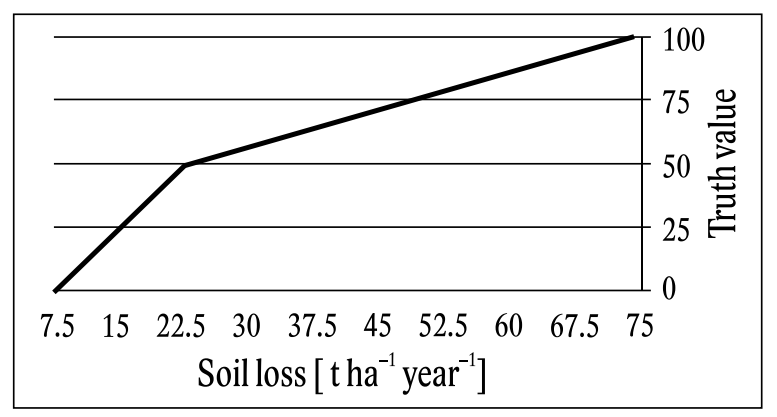

Fig. 3. Membership function for evaluation of the erosion control service of the forest.

The knowledge about the parameters of avalanches, which a forest might halt (secondary avalanche control service), or what type of forest is able to prevent the avalanche trigger (primary avalanche control service) were formalized to knowledgebase for evaluation of the avalanche control service of the forest (Sitko \& Scheer 2013). The 13 membership functions and 3 constant values were established for 9 criteria and the final value of the respective service was performed on basis AND aggregation by minimum-biased weighted average (Reynolds et al. 2002).

A similar approach of multicriteria aggregation is also used at the evaluation of wood production. The structure of knowledge base created for evaluation of wood production SE shows logic diagram (Fig. 4).

Domain values of stocking are used for evaluation of production area utilization. The productivity of stand is evaluated based on values of the index of the reduced growing stock level (Ired). Percentage of the assortments of I.-III.A assortment class formed domain values of membership function for evaluation of the quality of production and by the coefficient of slenderness (H/D ratio) is evaluated the safety of production. Breakpoints of membership functions for all criteria used for evaluation wood production service summarize Table 1. 


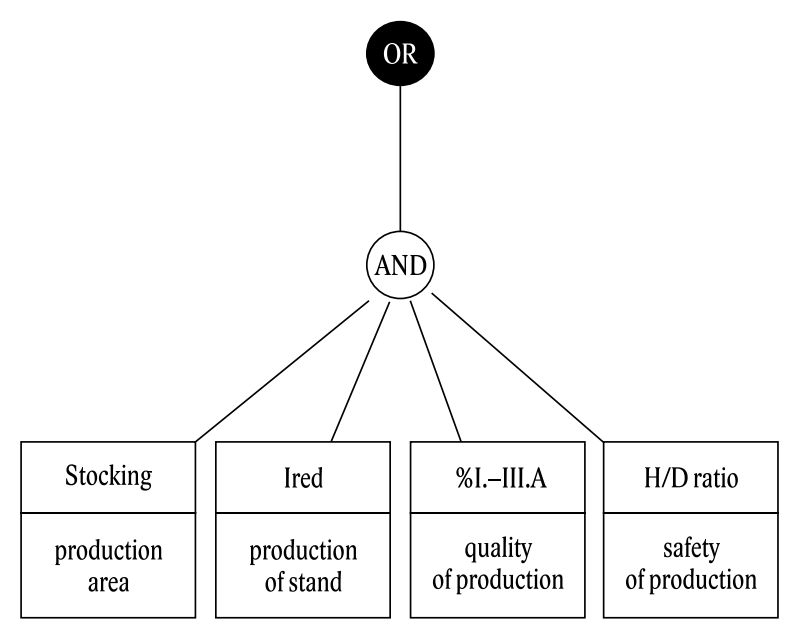

Fig. 4. The knowledge base for evaluation of wood production effect of the forest $\left(\mathrm{I}_{\text {red }}\right.$-index of reduced growing stock level, \%I.-III.A - the proportion of the assortments of I.-III.A assortment class, H/D ratio - coefficient of slenderness).

Table 1. Parameters of membership functions used for the evaluation of wood production.

\begin{tabular}{|c|c|c|c|c|c|c|}
\hline \multirow{2}{*}{ Criterion } & \multicolumn{5}{|c|}{ Breakpoints of membership functions } & \multirow{2}{*}{ Reference } \\
\hline & 0 & 50 & 100 & 50 & 30 & \\
\hline Stocking & 0.1 & 0.4 & $0.7-0.9$ & 1.3 & - & Fabrika (2006) \\
\hline Ired & 0.10 & 0.55 & 1.00 & - & - & Scheer \& Sitko (2007b) \\
\hline \%I.-III.A & 0 & 20 & 40 & - & 一 & Fabrika (2007) \\
\hline H/D ratio & - & - & $0.00-1.00$ & 1.71 & 2.00 & Fabrika (2007) \\
\hline TMVI* & 167 & 334 & 668 & - & - & Papánek (1978) \\
\hline
\end{tabular}

The value of cultural ecosystem services assigned for various levels of nature conservation presents Table 2 . Biotopes and areas included to NATURA 2000 receive the highest value 100 as does the fifth degree of territorial protection. Since not all three scenarios have been quantified, cultural SP and SE were evaluated at the same level.

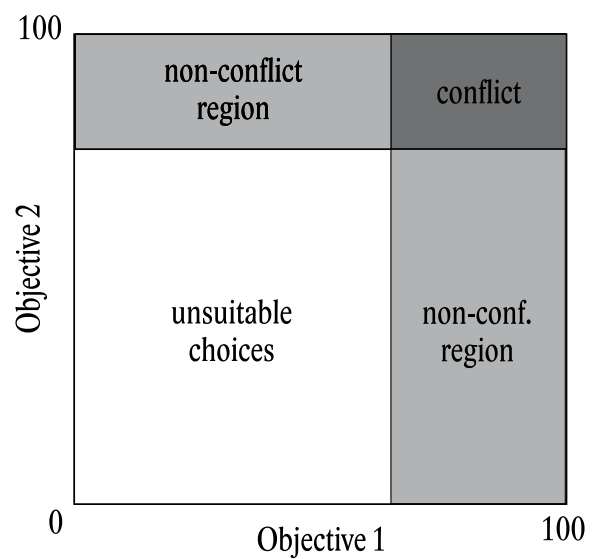

(a)
Table 2. Value of cultural ecosystem services assigned for 5 degrees of territorial protection.

\begin{tabular}{lccccc}
\hline Degree of territorial protection: & $1^{\text {st }}$ & $2^{\text {nd }}$ & $3^{\text {rd }}$ & $4^{\text {th }}$ & $5^{\text {th }}$ \\
\hline Truth value of cultural services: & 10 & 40 & 70 & 90 & 100 \\
\hline
\end{tabular}

The output of this phase is the creation of a suitability map (SM) for every evaluated SP and SE of ecosystem services. Four levels of importance of ecosystem services are distinguished:

- negligible - truth value less 10

- low - truth value within 10 - 39

- medium - truth value within 40-69

- high - truth value equal to or higher than 70

iv) Zoning of priority areas - is the final phase of the proposed workflow and includes the mapping of the spectrum of ecosystem services (SES). It is processed by the cross-classification procedure on individual SMs.

The allocation of support measures for valuated ecosystem services is based on an integrated approach to multi-objective forest planning. The proposed system allows to integrate multiple complementary objectives as well as conflicting ones. The procedure follows up the previous phase by finding out the difference between SP and SE. The greatest differences are represented by the sites with the highest disproportions between the potential and the real fulfillment of the investigated ecosystem services. The allocation of support measures for complementary services rests in the choice of territories with the highest disproportions. Ranking procedures built in the GIS software Idrisi (ClarkLabs 2012) have been used.

For the services with conflicting supporting requirements, the Multi-objective Land Allocation procedure (MOLA) was applied (Eastman 2016). This procedure allocates multiple conflicting objectives on the basis of the iterative reassessment of the score (SP-SE differences) in the conflicting zone until the defined area requirements are fulfilled (Fig. 5). The result of this

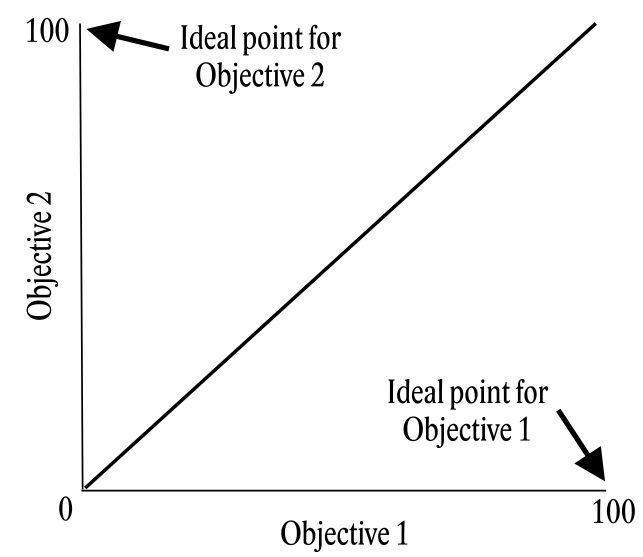

(b)

Fig. 5. The decision space formed by treating suitability values for each objective as a separate dimension. (a) The decision lines isolating the best regions to meet areal goals for the objectives, in the case of two objectives their intersect forms four regions: two regions of choices desired by one objective and not the other (and thus not in conflict), a region of choices not desired by either, and a conflicting region of choices desired by both; (b) The conflicting region is iteratively partitioned between objectives by means of a minimum-distance-to-ideal-point logic that partitions the decision space with a line whose angle is determined by the relative weight assigned to the objectives (modified according to Eastman 1995). 
procedure is finding a trade-off solution bringing about suitability optimization of the territory utilization to fulfill the defined objectives.

\section{Results}

Proposed four-phase workflow of the evaluation ecosystem services and zoning of priority areas was applied for evaluation of the potential (SP) and the effect (SE) of selected ecosystem services provided by the here investigated mountain forest. Separate subchapters bring results about mapping of the spectrum of selected ecosystem services (SES) and allocation of support measures for complementary as well as conflicting objectives in the model territory.

\subsection{Erosion control}

Evaluation of the erosion control has shown that the majority of the model territory has high SP. The resulting truth values of the service in the map of the suitability (SM) for erosion control potential have reached mean value 95.9 for the entire model territory. Distribution of values is given in the histogram (Fig. 6a). Variation of the service value is only $14 \%$, which refers to rugged terrain and a high slope inclination in the majority of the entire region. Mean slope inclination in the model territory is $29^{\circ}$.

SE quantified by the model MUSLE points out the fact that a real fulfillment of the erosion control service is on an acceptable level (Fig. 6b). The mean value of the service is 91.5 and the coefficient of variation increased to $24 \%$. It depends on a different state of vegetation cover in the model territory. Higher values of soil loss were found in terrain furrows, where the surface water flow is accumulated to gully and tree cover in these places is usually destroyed as a result of avalanche activities. On these sites, the greatest difference between the erosion control potential and effect of the forest has been found. A dominant part of slopes below the timberline is covered by forest stands which, in a suitable way, eliminate

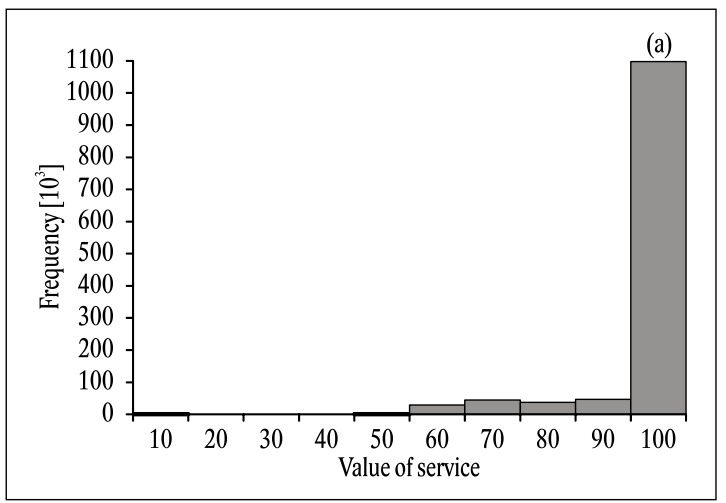

deleterious effects of water erosion.

The results obtained by its application in the forest management unit High Tatra were tested against the terrestrially measured values of soil loss. A high correlation between the measured and the modeled values has been found, and the coefficient of determination reached the value of 0.82 . Systematic overestimation of modeled results was corrected with a two-phase sampling by using a correction coefficient with a standard error of $\pm 22.6 \%$.

\subsection{Avalanche control}

The 452 ha (29\%) of forest stands with a truth value over 70 were classified into a category with the high avalanche control SP. However, a real fulfillment of the avalanche control service on the respective level is secured only by 114 ha of forest stands. This disproportion is obvious from the comparison of histograms in Fig. 7a, b. In summary statistics of avalanche control effect of the forest, this was expressed by a decrease in the mean truth value by 12 in comparison to avalanche control potential. This difference suggests that there are reserves in fulfillment of the avalanche control service. These results are, however, biased by database uncertainty, i.e. errors of the input data. A certain underestimation of the resulting SP arises from classification results of vegetation cover from the IKONOS images. Within this classification, the proportion of rowan occurrence was overestimated by $3.6 \%$ at the expense of conifers, which have a better avalanche control effect. This was manifested by a lower value of SE.

Model parameters used for the quantification of the maximum run-out distance of avalanches in the model territory are very favorable. The coefficient of determination reached the value of 0.98 , and the mean error of the model is $\pm 1.12^{\circ}$.

\subsection{Wood production}

Wood production service was evaluated at two scales. Wood production potential was evaluated for management groups of forest type (MGFT) and wood production

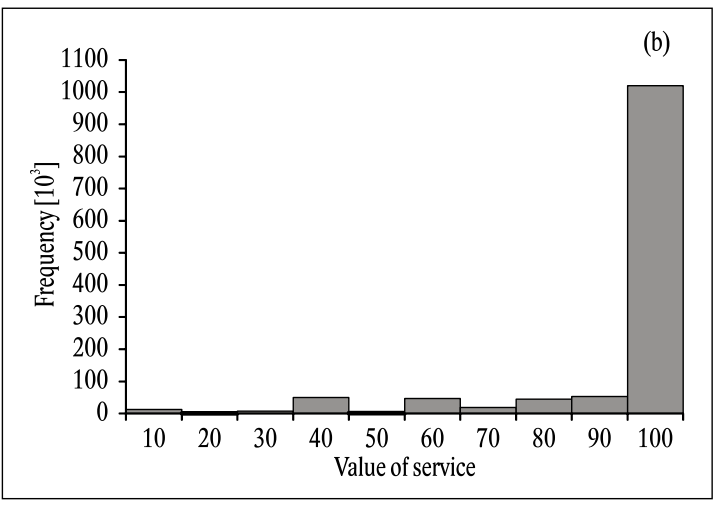

Fig. 6. Distribution of truth values of (a) erosion control potential, (b) erosion control effect of the forest. 

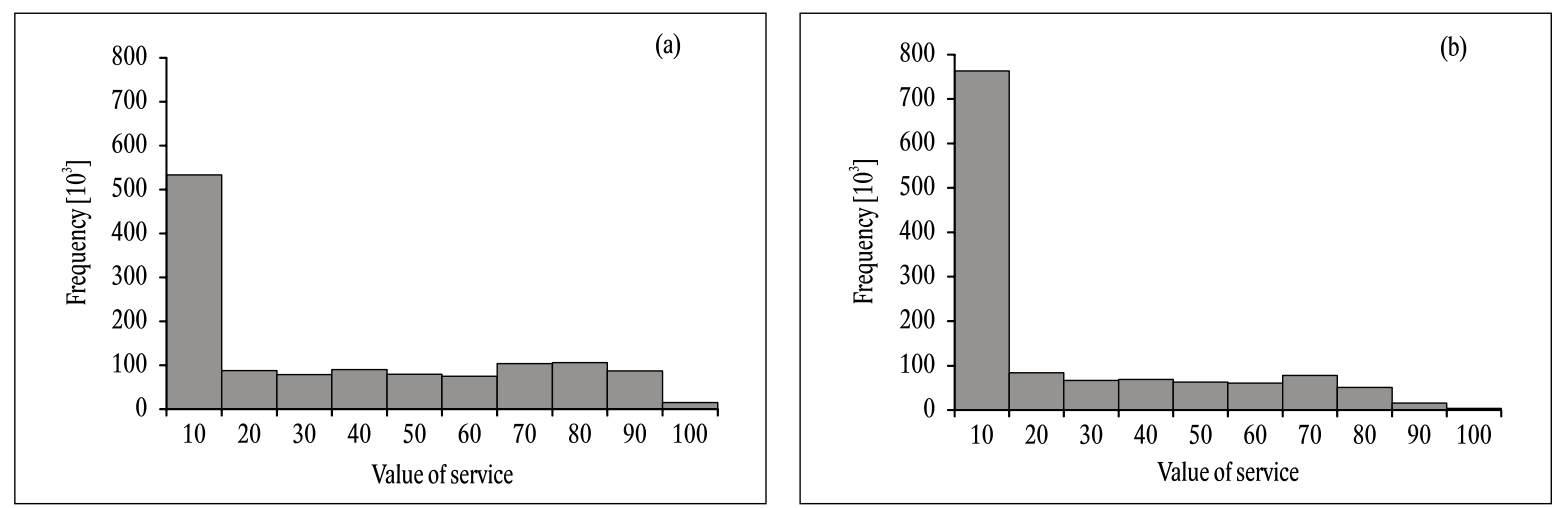

Fig. 7. Distribution of truth values of (a) avalanche control potential, (b) avalanche control effect of the forest.

effect for forest stands (compartments). SP of the whole model territory has the mean truth value 12 . Excluding the sites over timberline the mean value increased to 33. Distribution of the values is given in the histogram (Fig. 8a). Real fulfillment of wood production service was evaluated by the mean value of SE 8 , for the stands under timberline it is 22 . From the comparison of the distribution of wood production potential at Fig. 8a and effect at Fig. 8b, it can be seen disproportion, which can result from different scales used for evaluation SP and SE. Forest stands, in the evaluation of wood production potential were grouped into three categories of MGFTs. The highest frequency $(68 \%)$ has the category with the negligible wood production potential. The value of the service is up to 10 with dominance the sites over timberline. $23 \%$ of model territory is covered by forest stands under timberline with low production potential, $1 \%$ of forest stands have middle and $8 \%$ have high production potential. Frequency of the production effect is more continuous decreasing as it can be seen in Fig. 8b. Low wood production effect was evaluated by $25 \%$ of the model territory, middle effect by $1 \%$ and the high production effect has been evaluated less than $1 \%$ of the model territory. The rest of the entire territory ( $73 \%$ ) has negligible production effect, where dominate area close to or over the timberline, and partially area damaged by avalanches and wind-throw.

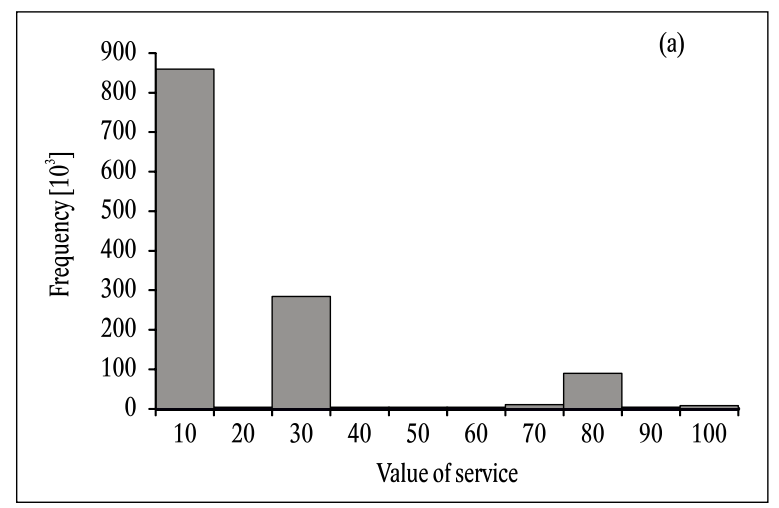

\subsection{Zoning of priority areas}

Finally, the evaluated ecosystem services were zoned over the model territory. The map of SES was created from suitability maps of SP. The combinations of three levels of the SP are expressed by numerical codes (Fig. 9).

Most frequently occurring priority area is $1-1-0$. This code defines a zone in which the cultural services have high priority (1-1-0), and also the soil-protection potential reaches a high level (1-1-0). The wood production potential is on a negligible level (1-1-0) in those sites. The area of the respective zone is $1270 \mathrm{ha}(51 \%$ of the model territory). Zone 1-1-3 makes up 35\% of the total area. Except the services mentioned above, a low wood production potential occurs in this zone. Another $9 \%$ of the model territory within the zone $1-1-1$ has high production potential and high culture and soil-protection potential. Other zone with a proportion higher than $1 \%$ is a zone $1-2-1$ with an area of 75 ha. It is the zone with a medium soil-protection potential.

The allocation of support measures for complementary objectives was aimed at soil-protection, particularly increasing the avalanche control effect of a forest. As for the conflicting objectives, the allocation of support for wood production service and avalanche control service of the forest was carried out. This was done in spite of the fact that the utilization of production potential is not considered in the model territory because of nature con-

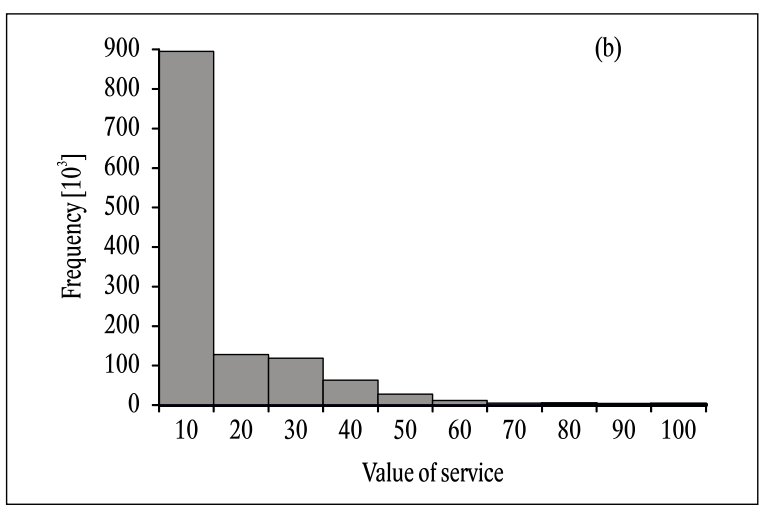

Fig. 8. Distribution of truth values of (a) wood production potential, (b) wood production effect of the forest. 
servation concerns. The aim of such allocation is to point out the versatility of the proposed workflow.

\subsubsection{Allocation of complementary objectives}

Based on the mapping of SES (Fig. 9), the cultural, avalanche control, and erosion control services were chosen as the priorities in the model territory. All of them are characterized by similar supporting measures, we therefore treat them as complementary objectives. As the evaluation phase suggested, the most notable gaps in the utilization of SP has the avalanche control. The requirement for the improvement of this service was estimated for a forest area of 200 ha and the measures were suggested to be taken in the sites with the highest avalanche control potential (Fig. 10a). Green areas represent an area of 200 ha in which the greatest differences between the evaluated avalanche control SP and SE were found. Adequate support measures can increase the avalanche control most efficiently in this area.

\subsubsection{Allocation of conflicting objectives}

The avalanche control and wood production service are considered here as conflicting objectives. Conflict is based on the incompatibility of the supporting measures these services when applied at the same site. The technique of the iterative re-evaluation of the conflicting zone has been used for the allocation of compromise solutions by means of the MOLA procedure. The following input parameters have been set:

- area requirements for the allocation of supporting measures for ecosystem services

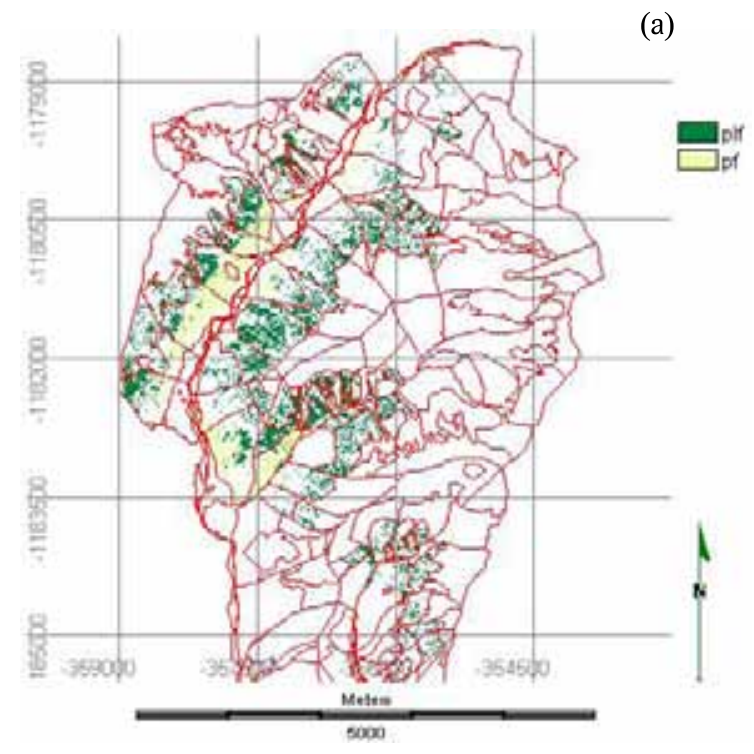

- map layers with values of differences between SP and SE for allocated services

- SM evaluating SP for allocated services

- weights determining the relative proportion that each objective will have in resolving conflicting claims for land (this value can reflect for example the proportion of costs to reach the conflicting objectives)

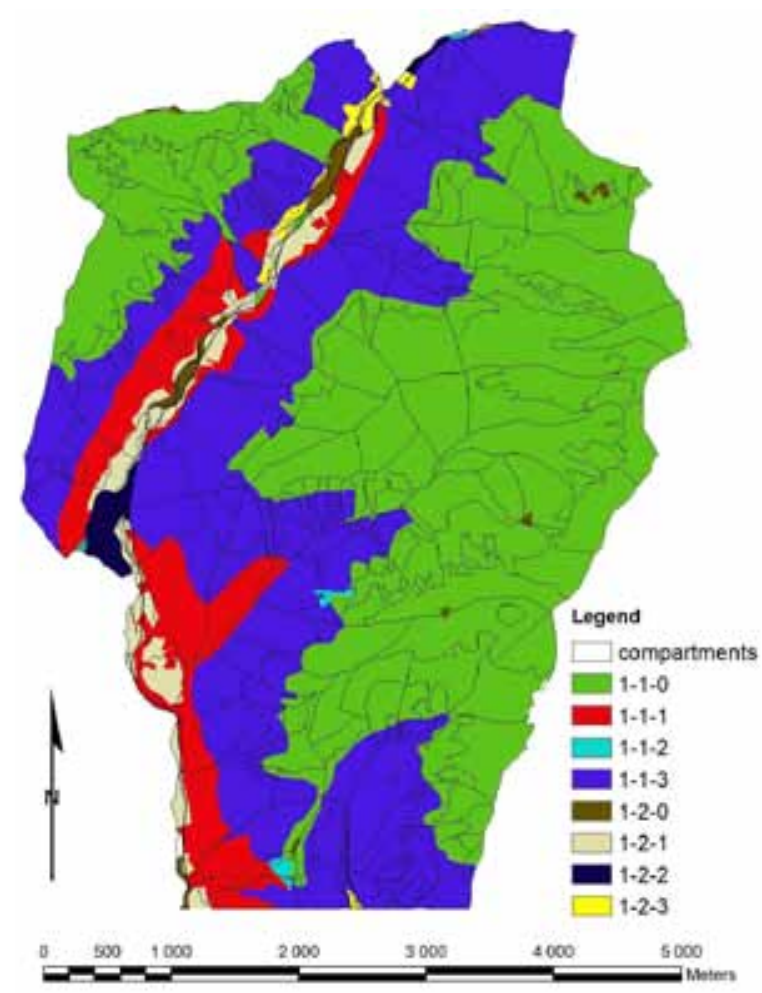

Fig. 9. Map of the spectrum of ecosystem services. Code 1 represents the high SP, 2 medium SP, 3 low SP and 0 negligible $\mathrm{SP}$, in order: cultural-soil protection-wood production.

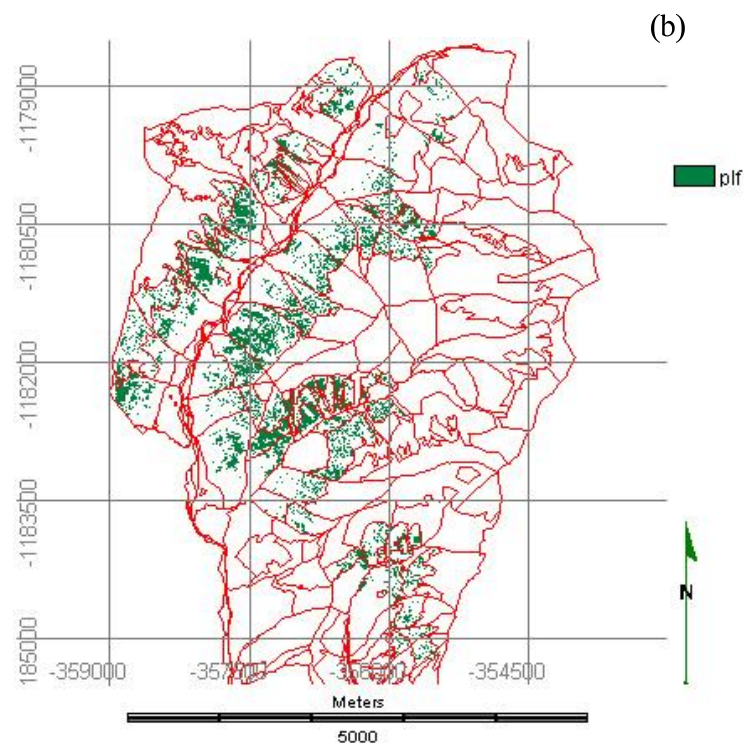

Fig. 10. Allocation of support measures for (a) complementary objectives (cultural, avalanche control and erosion control ecosystem services) to support the avalanche control service (acf); (b) conflicting objectives with compromise solution for avalanche control and wood production (pf). 
The real requirement for the support of the avalanche control service remained unchanged (200 ha) and that for the wood production represents 72 ha. The allocation of support measures aimed at sites with the high soil-protection and wood production potential. The SM of the avalanche control and wood production potential were used as auxiliary data optimizing the decisions in the conflicting zone. The maps were used for rectification of the allocation of the avalanche control service in places, where the production potential is the lowest one. A similar procedure was also applied for the production service. The equal importance (weight) was considered for both objectives.

The allocation result is shown in Fig. 10b. When comparing the allocated areas with the area chosen for support measures in the previous task, it has been found that an area of about 10 ha, where measures supporting the avalanche control we proposed to be taken, was within the compromise solution assigned to support of the wood production service. There was no significant spatial conflict of interests, which is also related to the character of both services. Production potential has been evaluated as the highest one in the valley of the model territory and the avalanche control service has been evaluated as significant in forest stands below the timberline and in the middle part of the slopes.

\section{Discussion}

Term priority area as a general term for areas where the ecosystem services and their priorities are important indicator for multi-objective forest planning brings Simoncic et al. (2013). This concept fits well into the proposed workflow of zoning of ecosystem services. The spectrum of ecosystem services (SES) was mapped in the model territory. SES reflects the diversity of services provided by the forest ecosystem, but also their importance (priority). It is an appropriate characteristic to differentiate objectives and measures within large forest areas and can be a spatial framework for planning possible financial compensations and subsidies for supporting of ecosystem services.

Intuitive expression of SP and SE by the truth values in the interval $[0,100]$, as well as transparency in the formalization of the knowledge base, facilitate public participation and cooperation in forest planning. Moreover, the fuzzy logic also allows for incorporating an uncertainty into the evaluation of ecosystem services. According to Pasadolas-Tato et al. (2013), it is a very important element in the decision-making process. Also, the simplicity of the heuristic approach of allocating priority areas in case of conflicting objectives by MOLA (Eastman 2016) supports a participative approach and transparency for allocation of support measures. A participative approach is enhanced with the possibility to define weights for the objectives in MOLA. I case of complex evaluation of many objectives the process of weights definition can be powered by methods like analytic hierarchy process or analytic network process (Saaty 2013).

Fuzzy logic and creation of membership functions are crucial in the evaluation phase of the proposed workflow. Subjectivity of the fuzzy models is often discussed (Marchini et al. 2009). We created the membership function for evaluation of erosion control service utilizing one complex quantified criterion - amount of soil loss, and the expert knowledge of tolerable or compensated erosion. A different approach was used in case of avalanche control service. The 13 membership functions were created for 9 criteria and those criteria were aggregated by logical operator AND. Sometimes the evaluation can be a more complex process, because of involving numbers of criteria or stakeholder preferences. For the purpose of objectivization of fitting the membership function, the artificial neural networks can be utilized (Jamsandekar \& Mudholkar 2013).

The allocation of SES for the model territory is considered as a partial output, because it does not include all ecosystem services. The hydrological service is one of the most important in the entire area and some forest stands are recognized as a source of reproduction material, and it was not the subject of evaluation. We put an accent to methodological aspect and in aim to refer versatility of proposed workflow were chosen just a few services from each of three core sections of ecosystem services (provisioning, regulation/maintenance, cultural) classified by CICES (Haines-Young \& Potschin 2018), before evaluation complex spectrum of ecosystem services in entire area.

Provisioning ecosystem services were represented in the current study with a wood production. When comparing the difference between the wood production potential and effect of the forest, the different spatial unit used for evaluation of SP and SE resulted in the inconsistency of evaluation. SE was evaluated for forest stands and SP was evaluated for management group of forest types (MGFT), what is spatially more aggregated unit. We recommend using the same spatial unit when evaluating SP and SE of any ecosystem service. It is important for planning of supporting measures which are in the proposed workflow based on finding the biggest differences between potential and effect of the forest on providing of ecosystem service.

The evaluation of cultural services has been included in the workflow by the form of constraints for utilization some of the provisioning services in favor of the planning of nature conservation objective. Five levels of territorial protection defined in our legislation and program NATURA2000 were used for evaluation purposes. This quite rough approach of evaluation can be supplemented by more detail ones. Mainly recreation and tourism ecosystem services can be addressed by numerous methodological approaches. Review on methods appropriate for the Carpathian protected areas was presented by Považan \& Kadlečík (2014). The here proposed workflow is appropriate to implement most of them. 
Importance of using accurate input data was documented in case of the evaluation of avalanche control SE. The credibility of the evaluation was decreased by database uncertainty resulting from overestimation of rowan in the classification of image data, at the expense of spruce proportion, which has bigger avalanche control effect. Certain level of database uncertainty is a natural phenomenon in the decision-making process. It is therefore important to verify the reliability of the input data and to take this uncertainty into account when making a decision.

Selection of the models used in the phase of quantification of ecosystem service was oriented to using empirical and semi-empirical models. Currently, the research is oriented towards the development of more complex numerical (process-based, physical) models, which have more generalvalidity. Adisadvantage of this group of the models is their high demands on input data and parameters. Our goal was to propose system applicable in practical planning and this is a reason why we have chosen models with lower demand on inputs, but appropriately validated in the conditions of mountain forests.

\section{Conclusions}

We proposed here an innovative four-phase workflow of the evaluation of forest ecosystem services and of the zoning of priority areas. The workflow integrates the knowledge system and analytical functionalities of GIS. The non-financial system utilizing fuzzy logic for the evaluation purposes proved to be appropriate to compare the priorities of individual ecosystem services. This evaluation method has become the basis for the application of special GIS techniques for the zoning of priority areas and allocation of support measures for cases complementary as well as conflicting objectives. Comparison of the case study results with the existing map of ecosystem services has proved that the proposed system feasibly maps the potential of ecosystem services and allocates the supporting measures for the needs of multi-objective forest planning. We consider the proposed workflow to be a useful means for precise zoning of priority areas mainly in mountain forests where the use of ecosystem services needs to be particularly sensitive. The presented case study has the ambition to highlight the advantages and disadvantages of the proposed workflow and used tools. However, the creation of a generally applicable system for the evaluation of priority areas in the framework of multi-objective forest planning requires interdisciplinary approaches involving different teams of experts on ecosystem services. The here proposed system can represent a valuable contribution to such an effort.

\section{Acknowledgment}

The study was supported by project VEGA 1/0217/17/8 and by the Slovak Research and Development Agency under the contracts No. APVV-16-0325, APVV-15-0265.

\section{References}

Bettelini, D., Cantiani, M. G., Mariotta, S., 2000: Experiences in participatory planning in designated areas: the Bavona Valley in Switzerland. Forestry, 73:187198.

Bettinger, P., Boston, K., Siry, J. P., 2009: Forest management and planning. Amsterdam, Elsevier, $331 \mathrm{p}$.

Boncina, A., 2011: Conceptual approaches to integrate nature conservation into forest management: a Central European perspective. International Forestry Review, 13:13-22.

Clark Labs, 2012: IDRISI Selva. Worcester MA, USA: Clark University.

Cubbage, F., Harou, P., Sillsa, E., 2007: Policy instruments to enhance multi-functional forest management. Forest Policy and Economics, 9: 833-851.

Haines-Young, R., Potschin, M., 2018: Common International Classification of Ecosystem Services, (CICES) V5.1, Guidance on the Application of the Revised Structure. Avaiable at: <https://cices.eu/content/ uploads/sites/8/2018/01/Guidance-V51-01012018. pdf>

Hytönen, M., 1995: History, evolution and significance of the multiple-use concept. In: Hytönen, M. (ed.): Multiple-use forestry in the Nordic countries. The Finnish Forest Research Institute, Helsinki, Finland, 460 p.

Eastman, J. R., 2016: TerrSet, Manual. Clark University 394 p. Avaiable at: <http://www. clarklabs.org/>

Eastman, J. R., Jin, W., Kyem, P. A. K., Toledano, J., 1995: Procedure for Multi-Criteria/Multi-Objective Decisions. Photogrammetric Engineering \& Remote Sensing, 61:539-547.

ESRI, 2011: ArcGIS Desktop: Release 10. Redlands, CA: Environmental Systems Research Institute.

Fabrika, M., 2006: Spatial decision support system with model SIBYLA and GIS. In: Deutscher Verband forstlicher Forschungskunde, Jahrestagung 29.-31. Mai, Staufen, p. 64-72.

Fabrika, M., Ďurský, J., 2006: Implementing tree growth models in Slovakia. In: Hasenauer, H. (ed): Sustainable Forest Management. Growth Models for Europe. Springer, Berlin - Heidelberg - New York, p. 315341.

Fabrika, M., 2007: Implementation of GIS and model SIBYLA in a spatial decision support system for forest management. In: Kappas, M., Kleinn, Ch., Sloboda, B. (ed.): Global change issues in developing and emerging countries: proceedings of the 2 nd Göttingen GIS and remote sensing days 2006, 4-6 October, Göttingen, Germany, p. 61-72. 
Grêt-Regamey, A., Sirén, E., Brunner, S. H., Weibel, B., 2017: Review of decision support tools to operationalize the ecosystem services concept, Ecosystem Services, 26:306-315.

Jamsandekar, S. S., Mudholkar, R. R., 2013: Self generated fuzzy membership function using ANN clustering technique. International Journal of Latest Trends in Engineering and Technology, Special Issue - IDEAS-2013, p. 142-152.

Kangas, A., Saarinen, N., Saarikoski, H., Leskinen, L. A., Hujala, T., Tikkanen, J., 2010: Stakeholder perspectives about proper participation for regional forest programmes in Finland. Forest Policy and Economics, 12:213-222.

Landscape Atlas of the Slovak Republic, 2013. Banská Bystrica: Slovak Environment Agency, Center of environment informatics. Avaiable at: http://geo. enviroportal.sk/atlassr/

Marchini, A., Facchinetti, T., Mistri, M., 2009: F-IND:A framework to design fuzzy indices of environmental conditions. Ecological Indicators, 9:485-496.

McClung, D. M., Mears, A. I., 1991: Extreme value prediction of snow avalanche runout. Cold Regions Science and Technology, 19, p. 163-175.

Moore, I. D., Wilson, J. P., 1992: Length-slope factors for the revised universal soil loss Equation: Simplified method of estimation. Journal of Soil and Water Conservation, 47:423-428.

Nikolov, Ch., Barka, I., Ferenčík, J., Hlásny, T., Vakula, J., Zúbrik, M. et al., 2010: Utilizing geographic information systems and remote sensing for assessment of changes in forest state in High Tatra after 2004. In: Konôpka B. (ed.): Research on spruce forests destabilized by harmful agents. Zvolen, National Forest Center Zvolen, p. 96-116.

Nordström, E. M., Nieuwenhuis, M., Bașkent, E., Biber, P., Black, K., Borges, J. et al. 2019: Forest decision support systems for the analysis of ecosystem services provisioning at the landscape scale under global climate and market change scenarios. European Journal of Forest Research, p. 1-21.

Papánek, F., 1978: Theory and practice of integrated multi-objective forest management. Forestry model No. 29, Zvolen, VÚLH Zvolen, 215 p.

Pasalodos-Tato, M., Mäkinen, A., Garcia-Gonzalo, J., Borges, J., Lämås, T., Eriksson, L., 2013: Assessing uncertainty and risk in forest planning and decision support systems: Review of classical methods and introduction of innovative approaches. Forest Systems, 22:282-303.

Považan, R., Kadlečík, J., 2014: Valuation of Ecosystem Services in Carpathian Areas with focus on SlovakiaGuidelines for rapid assessment. Avaiable at: < http:// www.ozpronatur.sk/wp-content/uploads/2014/02/ Valuation_methodology_EN.pdf $>$

Pechanec, V., Brus, J., Kilianová, H., Machar, I., 2015: Decision support tool for the evaluation of landscapes, Ecological Informatics, 30:305-308.
Pukkala, T., 2010: Introduction to multi-objective forest planning. In: Pukkala, T. (ed.): Multi-objective forest planning (Managing forest ecosystems). Springer, $216 \mathrm{p}$.

Reynolds, K. M., Rodriguez, S., Bevans, K., 2002: EMDS 3.0 User Giude: U.S. Department of Agriculture, Forest Service, ESRI, Inc, InfoHarvest, Inc.

Reynolds, K.M., Hessburg, P.F., 2005: Decision support for integrated landscape evaluation and restoration planning. Forest Ecology and Management 207:263-278.

Reynolds, K. M., Twery, M., Lexer, M. J., Vacik, H., Ray, D., Shao, G. et al., 2008: Decision support systems in natural resource management. In: Buurstein, V., Holsapple, C. (ed.): Handbook on Decision Support Systems. Springer, International Handbooks on Information Systems Series, Handbook on Decision Support System, 2: 499-534.

Reynolds, K. M., 2013: Implementing DSS in forestry practice: latest development, challenges and opportunities. In: Tuček, J., Smreček, R., Majlingová, A., Garcia-Gonzalo, J. (eds.): Implementation of DSS tools into forestry practice, Reviewed Conference Proceedings, Technical University in Zvolen, Slovakia, p. 11-18.

Simoncic, T., Boncina, A., Rosset, C., Binder, F., De Meo, I., Cavlovic, J. et al., 2013: Importance of priority areas for multi-objective forest planning: A Central European perspective. International Forestry Review, 15:509-523.

Scheer, L, Sitko, R., 2007a: Assessment of some forest characteristics employing IKONOS satellite data. Journal of Forest Science, 53:345-351.

Scheer, L., Sitko, R., 2007b: Estimation of Forest Production Employing IKONOS Satellite Data. In: Kappas, M., Kleinn, Ch., Sloboda, B. (ed.): Global change issues in developing and emerging countries: proceedings of the 2 nd Göttingen GIS and remote sensing days 2006, 4-6 October, Göttingen, Germany, p. 105-114.

Sitko, R., Scheer, L., 2013: Decision support in evaluating the avalanche control role of the forest. In: Tuček, J., Smreček, R., Majlingová, A., Garcia-Gonzalo, J. (eds.): Implementation of DSS tools into forestry practice, Reviewed Conference Proceedings, Technical University in Zvolen, Slovakia, p. 49-57.

Saaty, T., 2013: Analytic hierarchy process. Analytic network process. In: Gass, S. I., Fu, M. C. (eds.): Encyclopedia of Operations Research and Management Science, Springer Science+Business Media New York, p. 52-72.

Šály, R., Midriak, R., 1995: Water Erosion in Slovakia. Scientific work 19/I, Bratislava, VUPU, p. 169-175.

Tuček, J., Sitko, R., 2000: Spatial decision support systems. GeoInfo, no. 6/2000, Appendix: School of GeoInfo, 18 p. 